\section{Skeletal muscle features in myotonic dystrophy and sarcopenia: do similar nuclear mechanisms lead to skeletal muscle wasting?}

\author{
M. Malatesta \\ Dipartimento di Scienze Neurologiche, \\ Neuropsicologiche, Morfologiche e \\ Motorie, Sezione di Anatomia e Istologia, \\ Università di Verona, Italy
}

\section{Abstract}

In the cell nucleus, the gene primary transcripts undergo molecular processing to generate mature RNAs, which are finally exported to the cytoplasm. These mRNA maturation events are chronologically and spatially ordered, and mostly occur on distinct ribonucleoprotein (RNP)-containing structures. Defects in the mRNA maturation pathways have been demonstrated in myotonic dystrophy type 1 (DM1) and type 2 (DM2) whose characteristic multisystemic features are caused by the expansion of two distinct nucleotide sequences: (CTG) $n$ in the DMPK gene on chromosome 19q13 in DM1, and (CCTG)n in the ZNF9 gene on chromosome 3 q21 in DM2. By combining biomolecular and cytochemical techniques, it has been shown that the basic mechanisms of DMs reside in the accumulation of CUG- or CCUG-containing transcripts in intranuclear foci where several RNA-binding proteins necessary for the physiological processing of pre-mRNA are sequestered. Moreover, a nucleoplasmic accumulation of splicing and cleavage factors has been found in DMs. This suggests that the dystrophic phenotype could depend on a general alteration of the pre-mRNA post-transcriptional pathway. Interestingly, the accumulation of pre-mRNA processing factors in the myonuclei of DM1 and DM2 patients is reminiscent of the nuclear alterations typical of sarcopenia, i.e., the loss of muscle mass and function which physiologically occurs during ageing. Consistently, in an in vitro study, we observed that satellite-cell-derived DM2 myoblasts show cell senescence alterations and impairment of the pre-mRNA maturation pathways earlier than the myoblasts from healthy patient. These results suggest possible common cellular mechanisms responsible for skeletal muscle wasting in sarcopenia and in myotonic dystrophy.

\section{Skeletal muscle features in myotonic dystrophy}

In recent years, the role of mutations in nonprotein-coding regions has come to light in the pathogenesis of different neuromuscular diseases, ${ }^{1,2}$ so that the terms toxic RNA and spliceopathy have been increasingly referred to pathological conditions in which accumulation of mutant RNAs results in a deleterious gain-offunction deregulating transcript processing and protein synthesis in multiple metabolic pathways.

One of the best studied examples of RNAdominant disease is myotonic dystrophy (DM), an autosomal dominant disorder characterised by a variety of multisystemic features including muscular dystrophy with increased number of centrally located or clumped nuclei in muscle fibres, ${ }^{3}$ myotonia (muscle hyperexcitability), dilated cardiomyopathy, cardiac conduction defects, ${ }^{4}$ insulin-resistance, cataracts, ${ }^{5}$ and disease-specific serological abnormalities. ${ }^{6,7}$ Two forms of DM are presently known: the more severe DM1-Steinert's disease (OMIM 160900), caused by an expanded (CTG)n nucleotide sequence in the 3' untranslated region of the Dystrophia Myotonic Protein Kinase (DMPK) gene (OMIM 605377) on chromosome 19q13, ${ }^{8-10}$ and the milder form DM2 (OMIM 602688), caused by the expansion of the tetranucleotidic repeat (CCTG)n in the first intron of the Zinc Finger Protein (ZNF)-9 gene (OMIM 116955) on chromosome 3q21. ${ }^{11}$

In the cell nucleus, the gene primary transcripts undergo molecular processing to generate mature RNAs, which are finally exported to the cytoplasm: these mRNA maturation events are chronologically and spatially ordered, and mostly occur on distinct RNP-containing structures. ${ }^{12}$ By combining biomolecular techniques with the analysis in situ of the nuclear organization and molecular composition, it has been demonstrated that the expanded-CUG- or CCUGcontaining transcripts, in DM1 and DM2 cells respectively, are retained in the cell nucleus, and accumulate in the form of RNP-containing focal aggregates. ${ }^{13}$ These nuclear foci specifically sequester the alternative splicing regulators CUG-binding protein 1 (CUGBP1) and muscleblind-like 1 (MBLN1) protein, ${ }^{14-16}$ which are necessary for the physiological processing of premRNA, especially for contractile protein synthesis. ${ }^{17}$ These focal aggregates are considered as a biomolecular feature of DMs, and have been detected in several adult tissues as well as in cultured cells from DM patients..$^{13,18-23}$ These foci also sequester hnRNPs and snRNPs, i.e. splicing factors involved in the early phases of the premRNA processing, ${ }^{24}$ thus strengthening the hypothesis that the multifactorial phenotype of dystrophic patients may result from a more gen-
Correspondence: Manuela Malatesta, Dipartimento di Scienze Neurologiche, Neuropsicologiche, Morfologiche e Motorie, Sezione di Anatomia e Istologia, Università degli Studi di Verona, Strada Le Grazie 8, 37134 Verona, Italy. Tel. +39.045 .8027157 - Fax: +39.045 .8027163 .

E-mail:manuela.malatesta@univr.it

Key words: cell nucleus, myotonic dystrophy, sarcopenia.

Received for publication: 28 July 2012. Accepted for publication: 3 August 2012.

This work is licensed under a Creative Commons Attribution NonCommercial 3.0 License (CC BYNC 3.0).

(C) Copyright M. Malatesta, 2012

Licensee PAGEPress, Italy

European Journal of Histochemistry 2012; 56:e36 doi:10.4081/ejh.2012.e36

eral alteration of the pre-mRNA post-transcriptional pathway.

Recently, it has been demonstrated that MBNL1 accumulate in the nuclear foci during interphase but, at mitosis, the foci relocate to the cytoplasm where they undergo degradation, while newly-formed foci develop in the nucleus of the daughter cells as a consequence of $d e$ novo accumulation of expanded RNAs. ${ }^{25}$ Therefore, in proliferating cells, the cyclic release from the nucleus of the foci and their cytoplasmic degradation would prevent the massive intranuclear sequestration of nuclear factors; on the contrary, in non cycling cells, the nuclear foci do not undergo intracellular relocation/degradation and progressively increase in number and size. This dynamic behaviour of nuclear foci is compatible with the evidence that in DM patients the most affected organs or tissues are those where non-renewing cells are mainly present, such as the skeletal muscle, heart and the central nervous system, whereas cells from self-renewing tissues (such as skin fibroblasts or layering epithelial cells) are much less affected. Accordingly, measuring intranuclear foci in skeletal muscle biopsies taken from patients at different times it has been demonstrated that the MBNL1-containing foci actually become larger with increasing patient's age. ${ }^{25}$

In addition to the formation of intranuclear foci, DM1 and DM2 cells show an altered distribution of nuclear ribonucleoprotein (RNP)-containing structures and molecular factors responsible for pre-mRNA transcription and maturation. In particular, by means of ultrastructural immunocytochemistry on skeletal muscle biopsies from DM1 and DM2 patients, it has been shown $^{26,27}$ that splicing and cleavage factors accumulate in the intranuclear functional sites where they usually localize, sometimes ectopi- 
cally relocating also into nuclear RNP domains where they generally do not occur (unpublished results). This accumulation could hamper the functionality of the splicing machinery and slow down the intranuclear molecular trafficking thus reducing the metabolic activity of myonuclei, consistent with recent findings demonstrating a reduced protein synthesis in DM1 and DM2 myoblasts. ${ }^{28,29}$

\section{Skeletal muscle features in sar- copenia}

During ageing, the skeletal muscle undergoes a progressive loss of mass, strength and function, in the process known as sarcopenia. ${ }^{30,31}$ Sarcopenia affects healthy, physically active subjects: the rate of muscle loss in humans has been estimated to range 1 to $2 \%$ per year after age of fifty. Therefore, sarcopenia represents a great risk factor for frailty, loss of independence and physical disability in elderly, since it is associated with decreased functional performance, higher risk of falls and motor function impairment. The mechanisms underlying age-related skeletal muscle wasting and weakness are probably manifold and still remain to be fully elucidated; ${ }^{30}$ however, although no specific therapy is presently available to counteract its onset or progress, studies performed on humans and other mammals have stressed the importance of physical exercise as an effective, although still debated, approach to prevent or limit the agerelated muscle mass loss. ${ }^{32-36}$

Interestingly, the sarcopenic process is characterised by structural and functional alterations of the skeletal muscle that are reminiscent of myotonic dystrophy. In fact, the aged muscle shows grouped atrophy, fibre size variability and centrally located nuclei. ${ }^{37}$ In addition, factors involved in the post-transcriptional processing of pre-mRNA have been found to accumulate not only in the nucleoplasmic RNP-containing structures where they usually locate but also in ectopic nuclear domains. ${ }^{38-40}$ This intranuclear accumulation/ delocalization of RNP structures containing splicing and cleavage factors has been found not only in the skeletal muscle but also in other tissues (e.g., liver, brain) of aged mammals. ${ }^{41-44}$ Moreover, aged cells undergo malfunctions of the degradation systems both in the cytoplasm ${ }^{45}$ and in the nucleus ${ }^{46,47}$ with accumulation of crosslinked insoluble molecules (including non-coding RNAs) which hampers the intracellular transport mechanisms. This suggests that in ageing cells the entire production chain of mRNA, from its synthesis to the cytoplasmic export, becomes less efficient, likely contributing to the reduced capability of cells to positively react to metabolic stimuli, which typically occurs in elderly. This loss of responsive- ness would have particularly severe effects in skeletal muscles, where a misregulated protein turnover would result in a structural imbalance between muscle protein degradation and the restoring protein synthesis. ${ }^{48}$

\section{Concluding remarks}

A recent in vitro study ${ }^{49}$ reported that satellite-cell-derived myoblasts from DM2 patients show cell-senescence alterations (e.g., cytoplasmic vacuolisation, reduction of the proteosynthetic apparatus, accumulation of heterochromatin and impairment of the pre-mRNA maturation pathways) earlier than the myoblasts from healthy patients; moreover, when grown in a differentiation medium DM2 myoblasts fuse into multinucleated myotubes exhibiting structural defects similar to those observed in senescent myotubes from healthy patients. ${ }^{50}$ The early occurrence of senescence-related features in satellite cell-derived myoblasts suggests that satellite cells from DM2 patients have a reduced regeneration capability, which would contribute to the muscular dystrophic phenotype.

The cytochemical and ultrastructural evidence demonstrates that the skeletal muscle of DM patients shares intriguing similarities with the muscle from aged individuals in several nuclear features, especially in the altered nuclear RNP-containing structures involved in pre-mRNA transcription and splicing. This opens interesting perspectives on the role of the RNP nuclear components in the onset of muscle cell dysfunctions and encourages comparative studies aimed at detecting common cellular mechanisms at the basis of skeletal muscle wasting.

Finally, it is worth noting that the analysis in situ of the organization and molecular composition of nuclear domains is a powerful tool not only for getting information about the DNA/RNA pathways which govern cellular metabolism, but also for detecting the occurrence of cell dysfunctions related to pathological phenotypes..$^{51-53}$

\section{References}

1. Osborne RJ, Thornton CA. RNA-dominant diseases. Hum Mol Genet 2006;15:R162-9.

2. Wheeler TM, Thornton CA. Myotonic dystrophy: RNA-mediated muscle disease. Curr Opin Neurol 2007;20:572-6.

3. Vihola A, Bassez G, Meola G, Zhang S, Haapasalo H, Paetau A, et al. Histopa thological differences of myotonic dystrophy type 1 (DM1) and PROMM/DM2. Neurology 2003;60:1854-7.

4. Bachinski LL, Udd B, Meola G, Sansone V,
Bassez G, Eymard B, et al. Confirmation of the type 2 myotonic dystrophy (CCTG)n expansion mutation in patients with proximal myotonic myopathy/proximal myotonic dystrophy of different European origins: a single shared haplotype indicates an ancestral founder effect. Am J Hum Gen 2003; 73:835-48.

5. Meola G, Moxley RT $3^{\text {rd }}$. Myotonic dystrophy type 2 and related myotonic disorders. J Neurol 2004;251:1173-82.

6. Day JW, Ricker K, Jacobsen JF, Rasmussen LJ, Dick KA, Kress W, et al. Myotonic dystrophy type 2: molecular, diagnostic and clinical spectrum. Neurology 2003;60:657-64.

7. Savkur RS, Philips AV, Cooper TA, Dalton JC, Moseley ML, Ranum LP, et al. Insulin receptor splicing alteration in myotonic dystrophy type 2. Am J Hum Genet 2004;74:1309-13.

8. Brook JD, McCurrach ME, Harley HG, Buckler AJ, Church D, Aburatani H, et al. Molecular basis of myotonic dystrophy: expansion of a trinucleotide (CTG) repeat at the 3' end of a transcript encoding a protein kinase family member. Cell 1992;69:385-7.

9. Fu YH, Pizzuti A, Fenwick RG Jr, King J, Rajnarayan S, Dunne PW, et al. An unstable triplet repeat in a gene related to myotonic muscular dystrophy. Science 1992;255:12568.

10. Mahadevan M, Tsilfidis C, Sabourin L, Shutler G, Amemiya C, Jansen G, et al. Myotonic dystrophy mutation: an unstable CTG repeat in the 3' untranslated region of the gene. Science 1992;255:1253-5.

11. Ranum LP, Rasmussen PF, Benzow KA, Koob MD, Day JW. Genetic mapping of a second myotonic dystrophy locus. Nat Genet 1998; 19:196-8.

12. Fakan S. Ultrastructural cytochemical analyses of nuclear functional architecture. Eur J Histochem 2004;48:5-14.

13. Liquori CL, Ricker K, Moseley ML, Jacobsen JF, Kress W, Naylor SL, et al. Myotonic dystrophy type 2 caused by a CCTG expansion in intron 1 of ZNF9. Science 2001;293:864-7.

14. Miller JW, Urbinati CR, Teng-Umnuay P, Stenberg MG, Byrne BJ, Thornton CA, et al. Recruitment of human muscleblind proteins to (CUG)(n) expansions associated with myotonic dystrophy. EMBO J 2000;19: 4439-48.

15. Fardaei M, Rogers MT, Thorpe HM, Larkin K, Hamshere MG, Harper PS, et al. Three proteins, MBNL, MBLL and MBXL, co-localize in vivo with nuclear foci of expanded-repeat transcripts in DM1 and DM2 cells. Hum Mol Genet 2002;11:805-14.

16. Jones K, Jin B, Iakova P, Huichalaf C, Sarkar P, Schneider-Gold C, et al. RNA foci, CUGBP1, and ZNF9 are the primary targets of the mutant CUG and CCUG repeats expanded in myotonic dystrophies type 1 
and type 2. Am J Pathol 2011;179:2475-89.

17. Llorian M, Smith CWJ. Decoding muscle alternative splicing. Curr Opin Genet Develop 2011;21:380-7.

18. Taneja KL, McCurrach M, Schalling M, Housman D, Singer RH. Foci of trinucleotide repeat transcripts in nuclei of myotonic dystrophy cells and tissues. J Cell Biol 1995;128:995-1002.

19. Mankodi A, Teng-Umnuay P, Krym M, Henderson D, Swanson M, Thornton CA. Ribonuclear inclusions in skeletal muscle in myotonic dystrophy types 1 and 2. Ann Neurol 2003;54:760-8.

20. Mankodi A, Lin XL, Blaxall BC, Swanson MS, Thornton CA. Nuclear RNA foci in the heart in myotonic dystrophy. Circ Res 2005;97: 1152-5.

21. Cardani R, Mancinelli E, Sansone V, Rotondo G, Meola G. Biomolecular identification of (CCTG)n mutation in myotonic dystrophy type 2 (DM2) by FISH on muscle biopsy. Eur J Histochem 2004;48:437-42.

22. Cardani R, Mancinelli E, Rotondo G, Sansone V, Meola G. Muscleblind-like protein 1 nuclear sequestration is a molecular pathology marker of DM1 and DM2. Eur J Histochem 2006;50:177-82.

23. Cardani R, Mancinelli E, Giagnacovo M, Sansone V, Meola G. Ribonuclear inclusions as biomarker of myotonic dystrophy type 2 , even in improperly frozen or defrozen skeletal muscle biopsies. Eur J Histochem 2009; 53:107-11.

24. Perdoni F, Malatesta M, Cardani R, Giagnacovo M, Mancinelli E, Meola G, et al. RNA/MBNL1-containing foci in myoblast nuclei from patients affected by myotonic dystrophy type 2 : an immunocytochemical study. Eur J Histochem 2009;53:151-8.

25. Giagnacovo M, Malatesta M, Cardani R, Meola G, Pellicciari C. Nuclear ribonucleoprotein-containing foci increase in size in non-dividing cells from patients with myotonic dystrophy type 2 . Histochem Cell Biol 2012; D0I: 10.1007/s00418-012-0984-6

26. Malatesta M, Giagnacovo M, Cardani R, Meola G, Pellicciari C. RNA processing is altered in skeletal muscle nuclei of patients affected by myotonic dystrophy. Histochem Cell Biol 2011;135:419-25.

27. Malatesta M., Giagnacovo M., Cardani R., Meola G., Pellicciari C. Alteration of RNA processing in skeletal muscle nuclei of patients affected by myotonic dystrophy. Eur J Histochem 2011;55/suppl1:14.

28. Salisbury E, Schoser B, Schneider-Gold C, Wang GL, Huichalaf C, Jin B, et al. Expression of RNA CCUG repeats dysregulates translation and degradation of proteins in myotonic dystrophy 2 patients. Am J Pathol 2009;175:748-62.
29. Huichalaf C, Sakai K, Jin B, Jones K, Wang GL, Schoser B, et al. Expansion of CUG RNA repeats causes stress and inhibition of translation in myotonic dystrophy 1 (DM1) cells. FASEB J 2010;24:3706-19.

30. Thompson LD. Age-related muscle dysfunction. Exp Gerontol 2009;44:106-11.

31. Cruz-Jentoft AJ, Baeyens JP, Bauer JM, Boirie Y, Cederholm T, Landi F, et al. European Working Group on Sarcopenia in Older People,. Sarcopenia: European consensus on definition and diagnosis: Report of the European Working Group on Sarcopenia in Older People. Age Ageing 2010;39:412-23.

32. Marcell TJ. Sarcopenia: causes, consequences, and preventions. J Gerontol A Biol Sci Med Sci 2003;58:M911-6.

33. Bautmans I, Van Puyvelde K, Mets T. Sarcopenia and functional decline: pathophysiology, prevention and therapy. Acta Clin Belg 2009;64:303-16.

34. Zancanaro C, Mariotti R, Perdoni F, Nicolato E, Malatesta M. Physical training is associated with changes in NMR and morphometrical parameters of the skeletal muscle in senescent mice. Eur J Histochem 2007;51: 305-10.

35. Malatesta M., Fattoretti P., Giagnacovo M., Pellicciari C., Zancanaro C. Structural and functional features of skeletal muscle cell nuclei are modulated by physical exercise in old mice. Eur J Histochem 2011;55(Suppl. 1):14.

36. Curzi D, Salucci S, Marini M, Esposito F, Agnello L, Veicsteinas A, et al. How physical exercise changes rat myotendinous junctions: an ultrastructural study. Eur J Histochem 2012;56:e19.

37. Edstrom E, Altun M, Bergman E, Johnson H, Kullberg S, Ramírez-León V, et al. Factors contributing to neuromuscular impairment and sarcopenia during aging. Physiol Behav 2007;92:129-35.

38. Malatesta M, Perdoni F, Muller S, Zancanaro C, Pellicciari C. Nuclei of aged myofibres undergo structural and functional changes suggesting impairment in RNA processing. Eur J Histochem 2009;53: 97-106.

39. Malatesta M, Perdoni F, Muller S, Pellicciari C, Zancanaro C. Pre-mRNA processing is partially impaired in satellite cell nuclei from aged muscles. J Biomed Biotechnol 2010;2010:410405.

40. Malatesta M, Fattoretti P, Giagnacovo M, Pellicciari C, Zancanaro C. Physical training modulates structural and functional features of cell nuclei in type II myofibers of old mice. Rejuvenation Res 2011;14:543-52.

41. Malatesta M, Bertoni-Freddari C, Fattoretti P, Caporaloni C, Fakan S, Gazzanelli G. Altered RNA structural constituents in aging and vitamin E deficiency. Mech Ageing Dev 2003;124:175-81.

42. Malatesta M, Baldelli B, Battistelli S, Fattoretti P, Bertoni-Freddari C. Aging affects the distribution of the circadian CLOCK protein in rat hepatocytes. Microsc Res Tech 2005;68:45-50.

43. Malatesta M, Fattoretti P, Baldelli B, Battistelli S, Balietti M, Bertoni-Freddari C. Effects of ageing on the fine distribution of the circadian CLOCK protein in reticular formation neurons. Histochem Cell Biol 2007;127:641-7.

44. Malatesta M, Biggiogera M, Cisterna B, Balietti M, Bertoni-Freddari C, Fattoretti P. Perichromatin fibrils accumulation in hepatocyte nuclei reveals alterations of premRNA processing during ageing. DNA Cell Biol 2010;29:49-57.

45. Jameson CW. Towards a unified and interdisciplinary model of ageing. Med Hypotheses 2004;63:83-6.

46. Costanzo M, Cisterna B, Zharskaya 00, Zatsepina OV, Biggiogera M. Discrete foci containing RNAse A are found in nucleoli of HeLa cells after aging in culture. Eur $\mathrm{J}$ Histochem 2011;55:e15.

47. Costanzo M, Cisterna B, Zharskaya 00, Zatsepina OV, Biggiogera M. Synthesis, movement and destruction of RNAs in the nucleus. Eur J Histochem 2011;55(Suppl. 1):2.

48. Koopman R, van Loon LJC. Aging, exercise and muscle protein metabolism. J Appl Physiol 2009;106:2040-8.

49. Malatesta M, Giagnacovo M, Renna LV, Cardani R, Meola G, Pellicciari C. Cultured myoblasts from patients affected by myotonic dystrophy type 2 exhibit senescence-related features: ultrastructural evidence. Eur J Histochem 2011;55:e26.

50. Giagnacovo M, Costanzo M, Cardani R, Veneroni P, Pellicciari C, Meola G. Ultrastructural features of myotubes derived from myoblasts of patients affected by myotonic dystrophy type 2 , after senescence in vitro. Eur J Histochem2011;55(Suppl. 1):15.

51. Giagnacovo M, Cardani R, Meola G, Pellicciari C, Malatesta M. Routinely frozen biopsies of human skeletal muscle are suitable for morphological and immunocytochemical analyses at transmission electron microscopy. Eur J Histochem 2010;54:137-42.

52. Malatesta M, Meola G. Structural and functional alterations of the cell nucleus in skeletal muscle wasting: the evidence in situ. Eur J Histochem 2010;54:e44.

53. Cenni V, Capanni C, Columbaro M, Ortolani M, D'Apice MR, Novelli G, et al. Autophagic degradation of farnesylated prelamin A as a therapeutic approach to lamin-linked progeria. Eur J Histochem 2011;55:e36. 